\title{
Algumas considerações sobre a reforma urbana Pereira Passos
}

\author{
Some considerations about Pereira Passos urban reform
}

Mayara Grazielle Consentino Ferreira da Silva[a] (1)

[a] Universidade do Estado do Rio de Janeiro (UERJ), Rio de Janeiro, RJ, Brasil

Como citar: Silva, M. G. C. F. (2019). Algumas considerações sobre a reforma urbana Pereira Passos. urbe. Revista Brasileira de Gestão Urbana, 11, e10180179. https://doi.org/10.1590/2175-3369.011.e20180179

\section{Resumo}

O presente artigo é uma revisão de literatura sobre a Reforma Urbana Pereira Passos empreendida no Rio de Janeiro, então capital do Brasil, durante o mandato do presidente Rodrigues Alves e do prefeito Pereira Passos, entre 1902 e 1906. Ela representou a primeira grande intervenção urbana na cidade do Rio de Janeiro. 0 objetivo é discutir as reformas urbanas, visando trazer elementos ainda não tão explorados e possibilitando uma outra visão sobre as transformações urbanas e sobre o próprio prefeito, a fim de enriquecer a discussão e desmistificar alguns fatos. Nesse sentido, o que a historiografia chamou de Reforma Urbana Pereira Passos, na verdade, foram duas reformas empreendidas em um mesmo tempo e espaço, porém com autores e propostas diferentes. Além disso, cartas trocadas entre o prefeito e o engenheiro Alfredo Américo de Souza Rangel revelam opiniões do prefeito pouco esperadas, relacionadas às transformações na capital. 0 trabalho consiste em uma pesquisa bibliográfica e análise documental por meio de fontes oficiais e primárias.

Palavras-chave: Reforma urbana. Pereira Passos. Rio de Janeiro.

\section{Abstract}

This article is a review of the literature about the Pereira Passos Urban Reform undertaken in Rio de Janeiro, then capital, during the mandate of president Rodrigues Alves and mayor Pereira Passos, between 1902 and 1906. It was the first big intervention urban in the city of Rio de Janeiro. The objective is to discuss the urban reforms, aiming to bring elements not yet so explored, enabling another view about the urban transformations and about the mayor himself, enriching the discussion and demystifying some facts. In this sense, what the historiography called the Pereira Passos Urban Reform, in fact, were two reforms undertaken at the same time and space, however, with different authors and proposals. In addition, letters exchanged between the mayor and engineer Alfredo Américo de Souza Rangel may reveal opinions of the mayor little expected, related to the transformations in the capital. The work consists in a bibliographical research and documentary analysis through official and primary sources.

Keywords: Urban reform. Pereira Passos. Rio de Janeiro. 


\section{Introdução}

O presente artigo é uma revisão de literatura sobre a Reforma Urbana Pereira Passos empreendida no Rio de Janeiro, então capital do Brasil, durante o mandato do presidente Rodrigues Alves e do prefeito Pereira Passos, entre 1902 e 1906. Ela representou a primeira grande intervenção urbana na cidade do Rio de Janeiro. 0 objetivo é discutir as reformas urbanas, visando trazer elementos ainda não tão explorados e possibilitando uma outra visão sobre as transformações urbanas e sobre o próprio prefeito, a fim de enriquecer a discussão e desmistificar alguns fatos.

0 trabalho consiste em uma pesquisa bibliográfica que teve por objetivo conhecer as diversas contribuições sobre a Reforma Urbana Pereira Passos. 0 critério de escolha da literatura utilizada foram obras já consagradas dentro do tema e outras não tão conhecidas, mas que apresentam um olhar diferenciado acerca das reformas empreendidas no Rio de Janeiro, trazendo, assim, novas contribuições para a discussão. Além disso, também foi realizada uma análise documental por meio de fontes oficiais e primárias. As fontes oficiais consistem em dois relatórios elaborados na Comissão de Melhoramento da Cidade do Rio de Janeiro, criada em 1874, e no projeto da reforma urbana municipal, elaborado por Alfredo Américo de Souza Rangel, em 1903. Os dois relatórios e o projeto da reforma urbana municipal foram escolhidos para se fazer um comparativo entre o projeto que já vinha sendo proposto, do qual, inclusive, o prefeito Pereira Passos participou, com o projeto que de fato foi implementado. As fontes primárias consistem em cartas trocadas entre o prefeito e o engenheiro Souza Rangel entre 1906 e 1909. A análise documental de fontes primárias é importante por abordar o olhar de um dos atores diretamente envolvidos, nesse caso por trazer o próprio olhar do então prefeito do Rio de Janeiro, Pereira Passos, e um dos responsáveis pelas intervenções urbana e sanitária para o debate. A análise documental justamente contribui com o tema por trazer dados primários e oficiais, sendo essencial para a pesquisa trabalhar com esses documentos em si, e não somente com o que foi falado deles.

Durante o artigo será abordado o que significou a Reforma Urbana Pereira Passos - na verdade, ela representou duas reformas urbanas ocorridas em um mesmo tempo e espaço, porém com diferentes autores e propostas. Além da reforma urbanística propriamente dita, houve uma reforma sanitária realizada pelo médico higienista Oswaldo Cruz, sob responsabilidade de Rodrigues Alves. Antes de as transformações na capital terem ocorrido, já havia existido outras tentativas de mudanças urbanísticas. As reformas urbanas no Rio de Janeiro possuem semelhanças com as reformas europeias, especialmente a inglesa e a francesa. No primeiro ano do projeto urbanístico e sanitário, foram criados instrumentos jurídicos e financeiros para possibilitar sua execução, além de decretos para regular o uso da cidade. Enfim, cartas trocadas entre o prefeito e o engenheiro Alfredo Américo de Souza Rangel, responsável pela elaboração do projeto da reforma urbana municipal, trazem uma perspectiva do prefeito sobre alguns assuntos relacionados às reformas.

\section{O que foi, afinal, a reforma urbana Pereira Passos?}

A Reforma Urbana Pereira Passos foi uma tentativa de europeização e aburguesamento da cultura por meio de arquitetura, ideais e costumes. A Europa, especialmente as cidades de Paris e Londres, era tida como um modelo de civilização, progresso e modernidade a ser seguido. 0 progresso era sinal de desenvolvimento material; a civilização de comportamento pautado em um ideal burguês europeu; a modernidade no embelezamento e no saneamento relacionada a sair de um passado colonial e se adequar a um novo presente, certamente europeu. Dessa forma, as mudanças na capital tiveram um caráter urbanístico, sanitário e também comportamental, e a transformação da cidade se deu em um nível simbólico-espacial. Uma frase muito usual na época era "o Rio civiliza-se", que demonstra todo esse imaginário. 


\section{As duas reformas urbanas}

Na verdade, existiram duas reformas urbanas: uma executada pelo governo municipal, e outra executada pelo governo federal, ambas com ideais diferentes. Alguns autores, como Jaime Larry Benchimol (1992), Oswaldo Porto Rocha (1995), Sônia Gomes Pereira (1992) e André Nunes de Azevedo (1998, 2003), já relataram a existência desses dois projetos urbanísticos. Entretanto, esse último autor abordou mais detalhadamente as diferenças entre esses dois projetos, que serão tratadas a seguir.

A reforma municipal, gerida por Pereira Passos, por mais que não tenha deixado de lado os aspectos urbanísticos e sanitários, deu bastante importância para os aspectos comportamentais, muito em função do conceito de civilização que regeu a reforma do prefeito. De acordo com Azevedo $(1998,2003)$, um objetivo do governo municipal foi a ligação das diversas partes da cidade, associada a uma tentativa de difundir a civilização, em virtude de o Centro ser tido como um lugar civilizador. Para isso, a municipalidade ficou responsável pelo prolongamento, pelo alargamento e pela abertura de ruas que ligavam o Centro às Zonas Norte e Sul, com destaque para a Avenida Beira-Mar. Ainda ficou responsável por melhoramentos urbanos, como instalação de iluminação e de redes de água e esgoto. Por fim, assumiu a regulamentação dos usos urbanos, estabelecendo diversas medidas proibitivas, como andar descalço e sem camisa. A reforma municipal tinha como ideal o organicismo, cuja finalidade era interligar as diversas regiões da cidade ao Centro. Essa ligação era essencial para o bom funcionamento do todo. O conceito que regeu a reforma municipal foi a civilização por meio da ideia de individualidade, do respeito à lei, à ordem pública, da afinação do gosto estético e cultural.

Nessa perspectiva, houve uma tentativa - ainda que conservadora - de integração urbana proposta pelo governo municipal, por meio das vias construídas para ligar as diferentes áreas da cidade ao Centro, por ser visto como um lugar civilizador. Nessa direção, a integração urbana estava ligada à visão organicista de cidade do prefeito. Portanto, essa ligação não era apenas para melhorar a circulação de mercadorias, mas também para que os trabalhadores pudessem civilizar-se de acordo com um ideal burguês europeu, aderindo à sua visão de mundo e ao seu comportamento. Pereira Passos estimulou a circulação da população pelo Centro, só que tinha nesse ideal uma característica conservadora: ele não queria excluir as camadas populares da área central (Azevedo, 2003).

Nota-se que, dentro da historiografia, há divergências sobre a Reforma Urbana Pereira Passos. Para André Nunes de Azevedo (2003), houve uma tentativa de integração urbana entre diversos pontos da cidade, sendo que essa integração tinha um aspecto conservador, já que o prefeito queria que a população pobre fosse ao Centro para civilizar-se. Isto é, um dos objetivos da intervenção não seria simplesmente expulsar a população pobre do Centro, o que também não significa que ele quisesse que ela morasse nele. Por outro lado, a literatura costuma retratar a remodelação urbana como uma tentativa de excluir a população pobre do Centro, como argumentam Santana \& Soares (2009, p. 10): "Mas foram as gestões do Presidente Rodrigues Alves e do Prefeito Francisco Pereira Passos entre 1902 e 1906, que a modernização conservadora e excludente se afirma enquanto estratégia de expulsão dos desfavorecidos do núcleo metropolitano". Como ficará demonstrado nas cartas entre Pereira Passos e Souza Rangel, o prefeito comenta das habitações que ele fez aos trabalhadores e que a prefeitura deveria construir mais habitações localizadas na área central, próximas ao seu local de trabalho. Isso demonstra uma diferença entre a versão contada na historiografia e a versão do próprio prefeito.

Um ponto que merece ser abordado é o urbanismo culturalista de Pereira Passos, caracterizado por uma modernização conservadora. Isso significa que ela une a modernização do espaço urbano à conservação da tradição da cidade e de suas características naturais. Essa concepção culturalista se fez presente, por exemplo, no segundo relatório da Comissão de Melhoramento da Cidade do Rio de Janeiro, em 1876. Essa Comissão foi a primeira tentativa de renovação urbana, em que o prefeito criou um projeto alternativo, qual seja: a abertura de duas vias capazes de captar as brisas oceânicas, para evitar a derrubada dos morros do Castelo e do Santo Antônio. No entanto, essa ideia estava em oposição aos engenheiros e médicos que pediam a derrubada dos morros, pois acreditavam que estes impediam a circulação do ar, acarretando a concentração de miasmas, causadores de doenças. Pereira Passos, quando 
prefeito, manteve o Morro do Castelo, mesmo sendo pressionado, por vê-lo como parte da história da cidade. No mesmo relatório, ele respeitou a integração da cidade com o mar por meio da construção da Avenida Beira-Mar. Além do mais, ele valorizava a arquitetura colonial, que era vista como obsoleta, por isso ele preservou um importante imóvel histórico para a cidade: a Câmara Municipal (Azevedo, 2003).

A reforma federal, ocorrida no governo de Rodrigues Alves, dirigida principalmente por Lauro Muller e Francisco Bicalho, priorizou os aspectos urbanísticos e sanitários. Segundo Azevedo $(1998,2003)$, ela ficou a cargo da modernização do porto, do programa de saneamento, do prolongamento do canal do mangue e da abertura de três avenidas: a Avenida do Cais (atual Rodrigues Alves), a Avenida do Mangue (atual Francisco Bicalho) e a Avenida Central (atual Rio Branco). A principal obra do governo federal foi a modernização do porto, em função da qual foram realizadas as outras obras, uma vez que era necessário reestruturar o sistema viário da área portuária para facilitar a distribuição das mercadorias. A reforma federal tinha como ideal o mecanicismo, com isso a relação viária da cidade era de parte com parte, ou seja, a cidade não era pensada como um todo, podendo a parte ganhar maior importância que o todo, como foi o caso do porto. 0 porto era a obra mais importante e o símbolo de progresso, conceito que regeu a reforma a cargo do governo federal. 0 porto sempre foi uma importante fonte de riqueza, e sua modernização seria ideal para desenvolver economicamente o país e atrair imigrantes, porém seria necessário melhorar a imagem do Brasil no exterior, passando a ser visto como salubre e moderno.

A Avenida Central, mesmo sendo obra do governo federal, era o símbolo de progresso e de civilização, porque uniu as duas reformulações e, respectivamente, suas propostas. 0 governo federal atribuiu ao seu início um lugar de progresso, por ser próximo ao porto. Já o governo municipal marcou o final da Avenida como um espaço civilizador, por conter edifícios próximos responsáveis pela difusão da civilização, tais como o Teatro Lyrico, a Biblioteca Nacional, o Theatro Municipal e o Museu de Belas Artes (Azevedo, 2003).

Desse modo, como já dito, existiu uma reforma municipal e uma reforma federal, porém muitos autores que escreveram sobre o tema não evidenciaram as duas reformas urbanas que ocorreram em um mesmo espaço e tempo, descrevendo-as como um único projeto urbanístico executado por Pereira Passos. Além de a prefeitura não ter sido a única executora, o presidente Rodrigues Alves já havia anunciado a remodelação urbana antes de anunciar o prefeito para o cargo. Do mesmo modo, foi o engenheiro Alfredo Américo de Souza Rangel quem elaborou o projeto da reforma urbana municipal, aprovado pelo Clube de Engenharia. Diante de tudo apresentado, fica evidente que a reforma não foi idealizada por Pereira Passos exclusivamente, mas que outras pessoas participaram de sua elaboração e execução, mesmo que as reformas urbanas tenham ficado conhecidas pela historiografia como Reforma Urbana Pereira Passos.

\section{Reforma sanitária}

Além da reforma urbanística, também houve uma reforma sanitária, que ficou a cargo do governo federal, mais precisamente do Serviço de Saúde Pública do qual o médico higienista Oswaldo Cruz foi nomeado Diretor-Geral, em 1903. Antes de mais nada, é necessário relatar o pensamento médico da época que influenciou as medidas tomadas.

A medicina social que vinha se constituindo desde 1830/1840 passou a situar as causas das doenças não nos corpos dos indivíduos doentes, mas no próprio meio ambiente, por isso a medicina tornou-se preventiva. Esses médicos foram reivindicar a polícia médica, isto é, ter o poder para intervir em tudo o que pudesse vir a causar doenças, o que incluía demolir habitações insalubres, impondo um controle sob a cidade e sua população com relação às normas sanitárias. Para eles, a desordem urbana era a causadora da degeneração física e moral da população, tendo ela duas causas: a causa natural, que se encontrava na geografia e nas condições climáticas da cidade; e a causa social, que se referia às habitações coletivas e à falta de planejamento da cidade. Desde 1850, os médicos pediam uma intervenção urbana e a normatização do saber e da prática médica, combatendo o saber médico popular denominado charlatanismo (Benchimol, 1992; Pereira, 1992). As habitações populares eram consideradas produtoras 
dos comportamentos desviantes, como os vícios, e a origem das doenças que prejudicavam a saúde dos indivíduos. Assim, havia uma vinculação entre imoralidade, pobreza e saúde; logo, os pobres eram vistos como potenciais criminosos ou mesmo portadores de germes, então havia uma tentativa de disciplinar os indivíduos (Rago, 1985).

Oswaldo Cruz tinha o propósito de erradicar as epidemias de varíola, febre amarela e peste bubônica, e sua primeira campanha foi contra a febre amarela, em abril de 1903. Ele propôs acabá-la em quatro anos por meio da profilaxia - já com bons resultados em Cuba -, o que significava utilizar meios para se evitar a propagação da doença, eliminando o mosquito ou seus possíveis criadouros (Pereira, 1992). A prioridade ao combate à febre amarela se deu por ser a doença que mais contribuía para prejudicar a imagem do Brasil no exterior. 0 combate se dava de duas formas: pela persuasão, tentando mobilizar e conscientizar a opinião pública; e pela repressão, por meio das Brigadas Sanitárias e de leis rígidas. Oswaldo Cruz reivindicou a lei de notificação compulsória, que punia quem não comunicasse a doença (Del Brenna, 1985). No início de 1904, foi a vez do combate à peste bubônica, que era transmitida pela pulga do rato. Para acabar com essa doença, foi criado um novo cargo público, a dos compradores de ratos, que pagavam às pessoas por cada rato capturado, o que deu origem às criações piratas desses animais. Ademais, homens do governo percorriam a cidade espalhando raticida e recolhendo lixo (Benchimol, 1992). Em outubro de 1904, foi aprovado a lei da vacinação obrigatória em todo o país contra a varíola, mas, em 1905, o ex-prefeito Barata Ribeiro, então senador, conseguiu a revogação da lei, tornando a vacina voluntária (Del Brenna, 1985). 0 combate à febre amarela e à peste bubônica deram bons resultados, mas a campanha antivariólica, que dependia da aceitação da vacinação, não obteve resultados prósperos, pois houve forte rejeição popular.

\section{Projeto anterior e efetivo}

Antes da Reforma Urbana Pereira Passos, houve duas tentativas de efetivação das transformações urbanas: uma durante o Império e outra já na República.

Em 1874, foi constituída a Comissão de Melhoramento da Cidade do Rio de Janeiro, composta de três engenheiros (entre eles, estava Francisco Pereira Passos), na qual foram elaborados dois relatórios. No primeiro relatório (1875), o projeto incidia sobre a área norte, uma vez que o Centro dependia de um montante elevado de gastos e tempo. Essa área, que apresentava boas condições para o desenvolvimento da cidade, era a que mais necessitava de obras, as quais podiam ser realizadas com menor dificuldade e gastos. No segundo relatório (1876), que foi uma resposta às críticas do primeiro, as áreas central e sul também foram incluídas. Tal relatório evidencia que havia uma necessidade de transformar toda a cidade, botá-la abaixo e construir uma inteiramente nova, todavia isso seria uma utopia. Em ambos os relatórios, não estava exatamente definido qual seria o papel do governo na realização das obras. Foi sugerido que as obras fossem realizadas por meio de concessões do governo às empresas privadas que tivessem a capacidade de realizá-las, já que o governo não dispunha de tão elevada quantia, e que essas empresas teriam alguns benefícios, como a isenção da décima urbana (Passos et al., 1875, 1876). Com essa tentativa de reformulação urbana, quase nada foi realizado, pois o governo ofereceu concessões, mas a maioria delas não se efetivou. Inquestionavelmente, esse sistema de concessões não deu certo. Apenas quando o governo tomou para si a função de realizar a renovação urbana que, de fato, ela foi executada.

Em 1900, foi realizado o Congresso de Engenharia e Indústria produzido pelo Clube de Engenharia, cujo principal tema era o embelezamento e o saneamento da capital. Nele havia duas posturas em relação aos planos urbanísticos: uma era que o embelezamento da cidade já seria seu saneamento; e a outra era que o saneamento da cidade já seria seu embelezamento. Um problema para os engenheiros, que foi discutido no Congresso, era a falta de mão de obra qualificada. Na maioria das vezes, eram os mestres de obras que executavam as obras, mas, segundo os engenheiros, eles não tinham ideais de conforto e higiene (Pereira, 1992; Rocha, 1995). 
Conforme o projeto da reforma urbana municipal (1903) produzido pelo engenheiro Alfredo Américo de Souza Rangel, este associou o saneamento a uma remodelação arquitetônica, sobretudo por meio de abertura de vias, apesar de que o saneamento não dependia apenas disso. Até então, muito pouco do que havia sido planejado tinha sido de fato concretizado, seja pelo Estado, seja pelas concessões. Para Souza Rangel, planos urbanos anteriores projetaram vastas transformações em vez de apresentarem obras de utilidade imediata, como ele teria se preocupado em fazer, poupando as desapropriações para minimizar os gastos, visto que a abertura de ruas dependia de grandes desapropriações, as quais eram bastante dispendiosas. A área central foi o objeto de maior modificação urbana, apesar de a área norte mais próxima do Centro e a área sul também estarem inclusas (Prefeitura do Distrito Federal, 1903).

Então, existiram essas duas tentativas de realizar as transformações urbanísticas: a primeira de iniciativa do próprio Estado e a segunda por parte dos engenheiros, todavia os médicos também pediam por uma transformação urbana desde 1850. Desse modo, a renovação da cidade já era reivindicada décadas antes de ela ser de fato executada, constituindo, assim, o pensamento da época, como de médicos, engenheiros, juristas, estadistas e também de parte da elite.

\section{Semelhanças com a reforma francesa e inglesa}

O projeto urbanístico-sanitário foi inspirado na Europa, sobretudo nas cidades de Londres e de Paris. Contudo, ele não foi simplesmente copiado, havendo uma adaptação dos modelos europeus à realidade da cidade. Como revela Pereira (1992), havia dois modelos de reformulação urbana das cidades europeias: a inglesa, que era mais lenta, gradual e harmoniosa; e a francesa, que era mais drástica e radical.

Paris foi uma inspiração em muitos sentidos, no papel do Estado como idealizador, promotor e gestor da reforma; no modelo arquitetônico; nas obras feitas por meio de empréstimos particulares; e no valor dado à competência técnica de profissionais (Pereira, 1992). Na reforma inglesa, havia uma ausência de planejamento por parte do Estado, estando a burguesia à frente do processo de transformação urbana, enquanto, na francesa, já existia um planejamento do Estado (Rocha, 1995). Nessa direção, a reforma de Paris foi a opção adotada nas reformas do Rio de Janeiro.

Como a França serviu de modelo, muitos edifícios cariocas se aproximaram dos edifícios franceses, com o mesmo estilo arquitetônico: o ecletismo. Por exemplo, de acordo com Needell (1993), o Theatro Municipal, idealizado por Francisco Oliveira Passos, filho do prefeito, foi uma versão carioca da Ópera de Garnier, de Paris. Para Lenzi (2000), a Orla de Nice foi a provável inspiração para a Avenida Beira-Mar.

Apesar de Paris ter sido inspiração para o plano urbanístico do Rio de Janeiro, há diferenças entre as duas reformas. A reforma de Paris foi mais extensa e drástica; já a renovação urbana da então capital brasileira foi mais modesta, por exemplo, incidiu sobre uma parte da cidade e não foi tão definitiva e totalizadora (Pereira, 1992). Nesse sentido, a reforma do Rio de Janeiro se aproximou mais da reforma inglesa. Conforme Freire (1993), existia uma disputa entre Buenos Aires e Rio de Janeiro pelo título de "a Paris Tropical", e isso impulsionava as transformações urbanas. Esse sonho de ser Paris representava o desejo de anular uma situação periférica no mundo por meio da construção física e simbólica, tal como as capitais civilizadas europeias.

\section{3: o início das reformas urbanas}

De acordo com Pereira (1992), Benchimol (1992) e Del Brenna (1985), em 1903 foi criada uma série de instrumentos jurídicos e financeiros como uma forma de preparação para a realização dos planos urbanísticos. Eram eles: a nova lei de desapropriações, a alteração da lei orgânica do distrito federal, o arrocho fiscal, a centralização administrativa e a nova lei de regulamento de obras.

A nova lei de desapropriações: as obras precisavam de um grande número de demolições, especialmente na região central, o que dificultava sua realização, pois as tornavam muito caras. Em 1903, 
foi aprovada uma nova legislação, com isso a indenização ficava de dez a quinze vezes o valor locativo deduzido do imposto predial do ano anterior. Se a propriedade não tivesse imposto predial, a indenização seria calculada pelo aluguel do último ano. Com a nova legislação, os valores das indenizações diminuíram, então o cálculo era feito com base na declaração do valor dos imóveis para o imposto predial, porém os proprietários os declaravam abaixo do valor com o fim de pagarem menos impostos (Pereira, 1992; Benchimol, 1992).

A alteração da lei orgânica: no dia anterior à nomeação do prefeito, foi promulgado o decreto federal que suspendia por seis meses o Conselho Municipal, que era contrário à renovação urbana, delegando plenos poderes a Pereira Passos. A lei orgânica foi aprovada em 1903, ampliando os poderes do Executivo Municipal. No entanto, o legislativo continuou com o poder de aprovação do orçamento, podendo usá-lo como arma de barganha ou pressão contra o Executivo, por exemplo, atrasando a aprovação do orçamento. Com a lei orgânica, o prefeito detinha plenos poderes, podendo legislar por decretos, com exceção de criar e elevar impostos. A lei orgânica contribuiu para a intervenção urbana, uma vez que excluiu os obstáculos legais para sua realização (Pereira, 1992; Del Brenna, 1985).

$\mathrm{O}$ arrocho fiscal: para a efetivação das remodelações urbanas, foram realizados empréstimos, e, com isso, houve arrocho fiscal; então, impostos já existentes aumentaram, como o imposto predial que foi oferecido como garantia de empréstimos, e outros impostos foram criados, como a taxa sanitária e o imposto sobre terrenos não edificados. Houve também uma maior fiscalização sobre a arrecadação, o que aumentou a receita da municipalidade (Pereira, 1992; Benchimol, 1992).

A centralização administrativa: essa série de medidas necessitava de uma centralização administrativa, então o controle da máquina burocrática ficou nas mãos do prefeito, a fim de torná-la mais eficiente. Uma de suas medidas foi colocar em dia o pagamento dos funcionários municipais, visto que, anteriormente, havia o costume de atrasar os pagamentos de funcionários ou demiti-los para conter despesas (Pereira, 1992; Benchimol, 1992).

0 novo decreto de regulamento de obras: regulava a construção, a reconstrução, o acréscimo, os consertos dos imóveis, regulava as fachadas e os materiais que eram permitidos na construção, exigia plantas e construtores legalmente habilitados, regulava também o processo de concessão de licenças, entre outras exigências (Pereira, 1992).

Durante a chamada Reforma Urbana Pereira Passos, não houve uma aliança entre o Estado e o capital simplesmente. Na verdade, aconteceu um confronto do Estado com diversos interesses, como construtores, especuladores e proprietários, envolvendo instrumentos jurídicos e financeiros já citados, como a lei de desapropriações, o novo decreto de regulamento de obras e o arrocho fiscal. Para Del Brenna (1985), o capital internacional foi beneficiado, como o capital financeiro, por meio do financiamento de grande parte das obras; e os fabricantes estrangeiros, pelo fornecimento de materiais e de equipamentos para as construções. As companhias de serviço público também foram favorecidas, especialmente a Light and Power, que monopolizava o fornecimento de energia elétrica. Isso dizia respeito principalmente à Zona Sul e a seus moradores, onde os melhoramentos aconteceram de forma mais ampla. Segundo Abreu (2003), as melhorias aumentaram o valor do solo urbano em alguns pontos da cidade, acima de tudo no Centro e na Zona Sul, propiciando aos proprietários dos imóveis localizados nessas áreas extrair rendas consideráveis, além de favorecer a indústria da construção civil. As obras melhoraram a circulação interna e externa; com isso, houve uma diminuição do custo de circulação e do custo de produção, favorecendo vários setores da economia e o processo de acumulação do capital industrial. Setores ligados aos meios de transporte também se beneficiaram.

De acordo com Benchimol (1992), nesse processo houve um conjunto de interesses feridos, como os desapropriados não proprietários, os proprietários e os arrendatários. Os que não eram proprietários simplesmente perderam suas moradias, tendo que pagar por casas mais caras e insalubres. Os proprietários eram donos dos imóveis e viviam das suas rendas, embora tivessem conseguido indenizações. Os pequenos comerciantes e industriais alugavam esses imóveis e dependiam de uma clientela que residia e trabalhava no Centro. 
Como relatam Del Brenna (1985), Azevedo (2003, 1998), Freire (1993), Pereira (1992) e Benchimol (1992), além desses mecanismos, em 1903 a prefeitura instituiu uma série de decretos proibindo velhas usanças e fomentando novos usos da cidade. Essas medidas tinham por objetivo impor uma civilidade burguesa europeia e transformaram ou tentaram transformar o modo de vida, as atividades econômicas, os costumes, os hábitos e as formas de lazer da população, por razões econômicas, sanitárias ou simplesmente por uma ideologia burguesa. São exemplos dessas medidas proibitivas: a ordenha de vacas leiteiras em via pública, a venda de vísceras nas ruas, a vadiagem de cães, a mendicância, o ato de cuspir e urinar nas ruas.

\section{Cartas de Pereira Passos}

As cartas ${ }^{1}$ trocadas entre Francisco Pereira Passos e o engenheiro Alfredo Américo de Souza Rangel revelam opiniões do prefeito pouco esperadas, relacionadas às transformações na capital, possibilitando, assim, uma outra visão sobre o prefeito, o que é importante para entender o sentido que os próprios atores deram às suas ações. Essas cartas foram escritas entre 1906 e 1909, logo após o final do mandato do prefeito, durante viagens que ele realizou por diversos países. 0 prefeito, que ficou conhecido na literatura como "Haussmann Tropical", da obra de Jaime Larry Benchimol, e as reformas, que ficaram conhecidas como "a era das demolições", conforme Oswaldo Porto Rocha, são diferentes do olhar que o próprio prefeito tinha dele e das reformas urbana e sanitária, conforme será exposto nas cartas.

Em uma passagem da carta enviada de Paris no dia 3 de janeiro de 1907, o ex-prefeito compara Paris com o Rio de Janeiro e demonstra uma opinião diferente da qual ele foi associado durante a reforma municipal: a proibição de vendedores ambulantes por meio de decretos que regularam algumas práticas na cidade, conforme o trecho a seguir:

[...] sobre os passeios dos boulevards, levantaram-se desde as vésperas do natal, e ainda lá se conservam barraquinhas muito toscas de madeira e lona, onde se vende de tudo, mas principalmente brinquedos de toda espécie que algumas famílias pobres fabricam durante o ano em seus próprios aposentos. A municipalidade permite todos os anos esse gênero de negócio, porque dele vivem aquelas famílias. Foi pela mesma razão que nunca quis proibir os vendedores de balas nas ruas, que muita gente queria que eu proibisse no Rio de Janeiro.

Na literatura, o prefeito ficou conhecido por reprimir o comércio ambulante, nas palavras de Benchimol (1992, p. 281): “[...] o fato é que Pereira Passos usou, com todo o rigor, a sua máquina repressiva e fiscal contra os vendedores ambulantes [...]".

Em vários momentos nas cartas, o ex-prefeito demonstra que acompanhava as notícias sobre o Brasil por meio da leitura de jornais, inclusive em algumas delas ele se defendia de acusações que lhe eram feitas, como no fragmento da carta enviada de Paris em 13 de março de 1908:

O Paiz de 16 de fevereiro último publicou uma demonstração da dívida flutuante consolidada da prefeitura em novembro de 1906. Pareceu-me um (ilegível) de algarismos arranjados de propósito para tentarem provar que deixei a prefeitura crivada de dívidas e em estado de insolvabilidade. Sinto aí não estar para desmascarar mais esta patranha, mas espero em Deus ter ainda ocasião de fazê-lo. Enquanto, porém, não posso fazê-lo, peço o obséquio de ler aquela demonstração e dizer-me o que pensas a respeito, prometendo guardar toda a reserva sobre o que me disser. Na demonstração da dívida noto que incluíram no débito verbas que ali não podiam figurar e deixaram de incluir no crédito o saldo de 18.000 contos do empréstimo de 30.000 contos de 1906.

E como essas há muitas outras incorreções.

E no trecho da carta do dia 24 de novembro de 1908, também enviada de Paris:

${ }^{1}$ As cartas citadas foram cedidas pela historiadora Maria Isabel Ribeiro Lenzi. 
Disseram-me que na balaustrada do Russel colocaram umas estátuas alemãs de ferro fundido muito originais. Será verdade?

Fechou-se aí a exposição no dia 15 do corrente. Durou apenas três meses e custou milhares de contos. Não sei depois disso como ainda temos créditos para levantar empréstimos. Censurava-me por estar gastando grandes somas com melhoramentos da cidade, que aí estão e aí ficam, e já foram largamente compensados pelos benefícios que trouxeram. Entretanto, hoje, atira-se pela janela fora com essa exposição não sei quantos milhares de contos, e nada se diz!

Ou ainda na passagem da carta enviada de Paris no dia 10 de março de 1909:

Aqui não leio senão a Gazeta de Notícias e das diatribes do Jornal do Comércio não tenho tido conhecimento; mas imagino o susto que ele deve ter passado com a possibilidade da volta do Dr. Rodrigues Alves ao poder. E é natural que por esse motivo viesse de novo ladrar contra mim, não sabendo que em circunstância alguma quero mais ser prefeito. Não supunha, entretanto, que o Latif estivesse já esquecido da lição que o meu amigo lhe deu e se prestasse a servir de gato morto ao Jornal. A carta que ele escreveu contém tanta asneira que até passou do próprio jornal. A resposta está magnífica.

Em outro momento, ele relata sua decepção com o arrendamento das habitações coletivas feitas para os trabalhadores em sua gestão, como no fragmento da carta enviada de Paris no dia 11 de setembro de 1908:

Fiquei muito aborrecido quando soube que vão arrendar as casinhas que fiz construir para operários. Que destempero! A municipalidade gasta milhares de contos para fornecer ao proletariado habitações decentes e higiênicas, e quem vai lucrar são os rendeiros que as vão explorar em benefício próprio. Entretanto, seria tão fácil a prefeitura alugá-las diretamente aos operários por intermédio da diretoria de patrimônio e da polícia, sem aumento de pessoal. Os pretendentes se apresentariam com atestados das casas onde trabalhassem, sendo preferidos os que tivessem melhor comportamento e mais assiduidade ao serviço. A prefeitura contaria com um aluguel correspondente ao juro de $6 \%$ do capital empregado na construção dos prédios e no valor do terreno. Os operários que pagassem uma pequena taxa além do aluguel ficariam proprietários do prédio no final de certo número de anos, conforme a importância da taxa. Tudo isso cai por terra. Valha-nos Deus!

Em um trecho da carta enviada de Paris no dia 18 de outubro de 1908, ele retorna ao assunto sobre as habitações, demonstrando uma preocupação com a falta de habitações salubres para os trabalhadores, indicando que o governo deveria construir mais habitações para eles. Ademais, relata que as moradias para a classe trabalhadora deveriam ser construídas na área central, por serem próximas ao mercado de trabalho, embora ele tenha ficado conhecido por querer expulsar a população pobre do Centro:

[...] Parece, porém, que não é no fim de Copacabana deveria fazer seu ensaio de casas econômicas, mas sim na parte central da cidade, junto aos estabelecimentos industriais e comerciais, onde trabalham os operários, para que estes não tenham que fazer longas viagens para se recolherem à casa e possam tomar suas refeições com a própria família.

Não pense que as casas cuja construção iniciei por conta da municipalidade devam ser alugadas somente a operários da Prefeitura. Penso que podem sê-lo a quaisquer operários e diretamente pela prefeitura. Outra não deve ser a solução. Tenho opinião formada sobre o assunto.

A historiografia dos anos 1980 representada por Benchimol e Rocha, por exemplo, mostra um prefeito autoritário, o prefeito do "bota-abaixo", indiferente aos problemas das classes populares. Entretanto, nessas cartas, Pereira Passos demonstra preocupações e opiniões com a população mais pobre que não se ajustam à imagem negativa com a qual ele foi associado (Lenzi, 2003). Esses dois últimos fragmentos de cartas, dias 11 de setembro e 18 de outubro, revelam justamente essa divergência entre a historiografia e a visão do prefeito. 
Em último lugar, ele fala do jogo do bicho, dando uma opinião contraditória à forma como ele teria agido quando era prefeito - no caso, ele seria contrário ao jogo do bicho, perseguindo-o -, como na passagem da carta enviada de Paris no dia 1 de novembro de 1908:

Quando vejo que o governo continua a praticar violências na perseguição ao jogo do bicho, pergunto a mim mesmo se desse modo ele não vê que favorece o jogo das loterias, que é mais prejudicial do que aqueles. Se por causa do contrato que tem com a companhia de loterias não pode acabar com este jogo, feche ao menos os olhos ao jogo do bicho para ver se consegue assim pouco a pouco fazendo diminuir este.

A literatura costuma associar Pereira Passos à perseguição do jogo do bicho, como no trecho: "A ameaça supostamente representada pelo jogo do bicho foi associada às epidemias. Reprimir o jogo do bicho era também combater uma epidemia de imoralidade, ou mais uma manifestação de patologia urbana" (Mella, 2003, p. 115). No entanto, a literatura também aponta que o prefeito combatia o jogo de loterias, como no trecho: "Tenho procurado pôr termo à praga dos vendedores ambulantes de bilhetes de loteria [...]" (Benchimol, 1992, p. 278).

\section{Considerações finais}

Diante de tudo apresentado, fica exposta a complexidade da Reforma Urbana Pereira Passos, com seus diversos atores envolvidos e, consequentemente, suas diferentes perspectivas. 0 tema da pesquisa, longe de ter se esgotado, possui caminhos ainda pouco percorridos que podem ser mais bem debatidos. O objetivo do trabalho foi justamente trazer elementos, ainda pouco explorados, para a discussão, possibilitando um outro olhar sobre as transformações urbanas e sobre o prefeito. Documentos pessoais, como as cartas, podem apresentar pontos de vista dos atores relacionados às reformas urbanas, enriquecendo, assim, o debate sobre o assunto.

\section{Referências}

Abreu, M. A. (2003). Da habitação ao hábitat: a questão da habitação popular no Rio de Janeiro e sua evolução. Revista Rio de Janeiro, (10), 161-177.

Azevedo, A. N. (1998). Entre o progresso e a civilização: o Rio de Janeiro nos traçados de sua capitalidade (Dissertação de mestrado). Instituto de Filosofia e Ciências Humanas, Universidade do Estado do Rio de Janeiro, Rio de Janeiro.

Azevedo, A. N. (2003). A Reforma Pereira Passos: uma tentativa de integração urbana. Revista Rio de Janeiro, (10), 39-79.

Benchimol, J. L. (1992). Pereira Passos: um Haussmann tropical. A renovação urbana da cidade do Rio de Janeiro no início do século XX. Rio de Janeiro: Secretaria Municipal de Cultura, Turismo e Esportes, Departamento Geral de Documentação e Informação Cultural, Divisão de Editoração.

Del Brenna, G. R. (1985). O Rio de Janeiro de Pereira Passos: uma cidade em questão II. Rio de Janeiro: Index.

Freire, B. P. (1993). 0 sonho de ser Paris: rio de Janeiro e Buenos Aires na virada do século. In: Anais do V Encontro Nacional da Associação Nacional de Pós-graduação e Pesquisa em Planejamento Urbano e Regional (pp. 17-31). Belo Horizonte: ANPUR.

Lenzi, M. I. R. (2000). Pereira Passos: notas de viagens. Rio de Janeiro: Sextante Artes.

Lenzi, M. I. R. (2003). Francisco Pereira Passos - Possibilidade de um outro olhar. Revista Rio de Janeiro, (10), 133141. 
Mella, J. L. V. (2003). Temporalidade e identidade. 0 jogo do bicho no Rio de Pereira Passos. Revista Rio de Janeiro, (10), p. 109-124.

Needell, J. D. (1993). Belle époque tropical: sociedade e cultura de elite no Rio de Janeiro na virada do século. São Paulo: Companhia das Letras.

Passos, F. P., Jardim, J. R. de M., \& Silva, M. R. (1875). Primeiro relatório da comissão de melhoramento da cidade do Rio de Janeiro. Rio de Janeiro: Typografia Nacional.

Passos, F. P., Jardim, J. R. de M., \& Silva, M. R. (1876). Segundo relatório da comissão de melhoramento da cidade do Rio de Janeiro. Rio de Janeiro: Typografia Nacional.

Pereira, S. G. (1992). A reforma urbana de pereira passos e a construção da identidade carioca. Rio de Janeiro: ECO/UFRJ.

Prefeitura do Distrito Federal. (1903). Melhoramentos da cidade projetados pelo prefeito do distrito federal, Dr. Francisco Pereira Passos. Rio de Janeiro: Typografia da Gazeta de Notícias.

Rago, L. M. (1985). Do cabaré ao lar: a utopia da cidade disciplinar (3. ed.). Rio de Janeiro: Paz e Terra.

Rocha, O. P. (1995). A era das demolições: cidade do Rio de Janeiro, 1870-1920 (2. ed.). Rio de Janeiro: Secretaria Municipal de Cultura, Departamento Geral de Documentação e Informação Cultural, Divisão de Editoração.

Santana, F. T. M., \& Soares, M. R. (2009). Reformas Passos: cem anos de uma intervenção excludente. In XII Encuentro de Geógrafos de América Latina (pp. 1-12.). Montevideo: EGAL.

Editor: Fábio Duarte.

Recebido: Dez. 16, 2018

Aprovado: Fev. 8, 2019 